\title{
CRITICAL ANALYSIS AND INFERENTIAL POTENTIAL OF SABLE ISLAND HISTORICAL SOURCES
}

\author{
AARON MIOR* \\ 57 Beaufort Drive, Ottawa, Ontario, Canada, K2L $2 B 9$
}

\begin{abstract}
Over four hundred years of history has been documented in a variety of primary and secondary resource materials regarding the cultural maritime landscape on Sable Island. While this wealth of resource data provides intricate details regarding historical human occupation on the island, in order to derive conclusions and inferences from the data a critical analysis of this resource material should be conducted. The remote location of Sable Island, and the comparably limited historical human occupation, presents a unique, primarily undisturbed, maritime landscape to investigate scientifically. This paper examines the ability to study and analyze the historical events related to the island's maritime history which specifically occurred on the island. The essential purpose of this article is to evaluate the variety of historical sources documenting the maritime history on Sable Island and argue for the classification of these sources based on their perceived reliability and accuracy. Only when the historical sources have been critically analyzed can they be utilized to provide greater inferential potential and confidently test hypotheses to develop relevant conclusions regarding events which specifically occurred directly on the island.
\end{abstract}

\section{INTRODUCTION}

Sable Island has many distinctive features within its unique landscape to investigate, including a number of natural and physical scientific phenomena. The island also has a long and storied cultural history extending back to at least the $16^{\text {th }}$ century, with the first documented shipwreck on Sable occurring in 1583 and the first known attempt to establish a permanent settlement on the island in 1598 . By the late $18^{\text {th }}$ century, Sable Island had already become associated with a number of prominent maritime disasters and the significant number of vessels wrecking on its shores suggests it had already began to earn its reputation as the "Graveyard of the Atlantic". 
The wreck of Francis at Sable Island in 1799, with the loss of all on board including Prince Edward and other distinguished passengers during a voyage from England to Halifax, provided the incentive to establish a government-funded permanent residence on the island in an effort to prevent additional losses to both human lives and commercial economic commodities. In October 1801, the Sable Island Humane Establishment was initiated with James Morris enacted as the first Superintendent. The main purpose of the Humane Establishment, the first of its kind in North America (Campbell 1976), was to provide aid to all shipwreck victims and salvage materials from wrecked vessels to minimize significant losses.

This permanent settlement on Sable Island produced a wealth of first-hand historical documentation including the detailed daily journals maintained by the Superintendent's and the frequent correspondence between the island residence and government officials on the mainland documenting general island activities. The Humane Establishment was maintained until 1958, when it was discontinued due to the decreasing number of shipwrecks occurring on the island, although human occupation has continued on the island to the present day.

The varied episodes of occupation and settlement on Sable Island, in addition to the tales of tragedy and survival, provide a significant amount of historical material detailing the cultural history on Sable Island. In addition to the documentation produced since the initiation of permanent human occupation on the island in 1801, a significant number of resources also exist detailing historical episodes prior to the $19^{\text {th }}$ century. This data set comprises a wealth of primary and secondary source material available to investigate the island's unique maritime cultural history.

\section{TYPES OF HISTORICAL SOURCES}

Before an historical analysis of any site can be undertaken, a serious attempt must be made to gather and synthesize all research material available to the investigator (Gould 1983, Cotter 1978, Hume 1978). In the case of Sable Island, the vast amount of reference materials detail over four hundred years of the island's cultural history. Partially due to its alluring history of shipwrecks, survivor's camps and numerous attempts and failures at establishing settlements on Sable, in addition 
to the general public's interest and intrigue of this island, a wealth of historical documentation has been produced and published.

In an effort to organize and synthesize the historical material, a research database has been created encompassing both primary and secondary resource material. This research archive incorporates a variety of primary source material including over three hundred documents obtained from archival institutions, 44 years of partial or complete Superintendent Journals dating between 1801 and 1912 and over 1,200 newspaper articles spanning from 1737 to 1999. In addition to the 29 published secondary sources, 16 Sable Island shipwreck lists produced between 1835 and 2007 and 14 Sable Island shipwreck maps dating between 1824 and 1994 have also been consulted.

While these historical resources provide valuable insight into the cultural history of Sable Island, they also contain inherent bias. Many of the primary source documents available for consultation were produced with minimal regard for posterity, rather they were intended to inform, influence, entertain or sometimes even mislead contemporaries (Tosh 2015). It is important to remember then that these primary documents were not produced with the intention to be used for academic research, but rather in many cases to convey messages deemed relevant by the author.

In regards to the secondary sources, many were produced with the intention of public consumption rather than an emphasis on historical documentation. Within the secondary source material there are numerous discrepancies detailing historical events on the island, including the shipwreck lists and maps where no two sources are identical. Many authors have neglected to provide their references, preventing the ability to independently analyze the data without completing an audit of the historical sources available. This is necessary because in order to attempt valid interpretations from the data, the reliability of the resources must be determined.

\section{RELIABILITY OF HISTORICAL SOURCES}

The inferential potential of the Sable Island data set is determined by the reliability and accuracy of the historical material. Therefore, an attempt must be made to evaluate what resources can be deemed reliable enough to be utilized for testing hypotheses or making relevant inferences. 
As Campbell (1975) has recognized, "the serious historian may point out that many of the highly-coloured tales of Sable horror are, if not definitely fabricated, certainly unproven." While this statement is not suggested to relate to all resources documenting Sable Island historical events, a significant number of discrepancies can be identified in the material available. The large data set detailing Sable Island historical events provides a significant documentary resource spanning over four hundred years of cultural history, although the strength of the inferences and conclusions to be investigated from these resources relies on the validity of the data utilized.

\section{CLASSIFICATION OF SABLE ISLAND HISTORICAL SOURCES}

No source can be used for historical reconstruction or determine analytical inferences until some estimate of its standing as historical evidence has been made (Tosh 2015). In an effort to differentiate the reliability of Sable Island historical sources documenting events which occurred on the island, they have been classified into six categories based on their perceived reliability regarding the topic or event described therein. The primary resource materials have been divided into two classes; "Authoritative" and Other Primary Sources, with the secondary sources separated into four categories; Contemporary, Later Secondary Sources, Shipwreck Lists and Shipwreck Maps.

A document is considered to be an "Authoritative" source if the author was physically on Sable Island when the event occurred, the document is an original copy either in the author's handwriting or signed by the individual and it must have been written within one year following the event described. Examples of "Authoritative" sources include original journals written by Humane Establishment Superintendents and documents written or signed by individuals associated with vessels wrecked at the island. While no historical source can ever truly be labelled as "Authoritative", the intention of this classification is to identify these sources as the highest order of reliability and distinguish them from other types of primary source material.

All other primary source documents that do not meet the criteria for "Authoritative" sources are classified as "Other Primary Sources". These resources include copies of documents and those written more than one year following the event described, even in circum- 
stances where the author was on the island when the event occurred. Additional examples include inter-governmental documentation and correspondence written between parties interested in specific events who were not on the island when the event occurred such as vessel owners or insurance agents.

The secondary source material is divided into four classes based on date of composition or type of resource. Contemporary resources are defined as any secondary source originally written during the Sable Island Humane Establishment Period (1801-1958) and specifically details events during this period. Examples of contemporary secondary sources include Janet Carnochan's Shipwrecked on Sable Island suggested to have been originally composed in 1879, but not published until 1986 and James Farquhar's autobiographical publication Farquhar's Luck, understood to have been written in 1929, but not published until 1980. While some historians may consider these publications to be primary source materials, a distinction must be made that they are quite different in context and product.

Autobiographies may be very revealing of mentality and values, but as a record of events they are often inaccurate and selective to the point of distortion (Tosh 2015), and although no primary or secondary source is void of bias, the classification of these Contemporary Secondary Sources is based on a number of factors. One reason is that a significant amount of time elapsed between when these contemporary secondary sources were originally composed and when they were finally published, suggesting the possibility that the original manuscript may have subjected to editing by people other than the original author. Also, although these publications were originally written by those who are suggested to have participated in events on the island, they did not witness all events described in their publications, and therefore some events described are based on secondary dissemination of knowledge. While some events detailed in these sources dating to the period when the author was physically on the island can be corroborated by comparative primary sources, significant discrepancies are exposed when compared to available primary source documents for many other events described in these publications.

Later secondary sources are defined as those that were either written after the Sable Island Humane Establishment ceased to exist under government authority in 1958, or were written during the Humane Establishment Period, but describe events prior to its initiation in 1801. 
The distinction between these two classifications are based on the assumption that contemporary secondary sources would have been originally composed closer to the time of the actual event described and were likely to be based on local knowledge rather than historical research. While one class of secondary source is not necessarily suggested to represent a greater degree of reliability, they do provide alternative data sets for comparative analysis.

The final two classes of secondary resource material comprise shipwreck lists and maps. All shipwreck lists consulted are classified together regardless of date of composition. These resources represent an independent entity focusing on compiling the number of shipwreck events that are suggested to have occurred at Sable Island as a whole, rather than describing the aspects and consequences of each individual event. Shipwreck maps are also classified together regardless of date of composition as they are essentially lists with the added spatial component. Some shipwreck maps also provide details regarding landscape features on the island during the Humane Establishment Period such as buildings and other areas of occupation and relevance.

Before the researcher can properly assess the significance of a source, they need to determine how, when and why it was created (Tosh 2015). This classification system is based on these assessments, with the historical data differentiated in the authors' research by assigning a different colour to each class. For example, "Authoritative" sources are presented in red, "Other Primary Sources" in blue, "Contemporary Secondary Sources" in green, "Other Secondary Sources" in orange, shipwreck lists in purple and shipwreck maps in brown. When all the data for a particular event is combined, this colour differentiation provides the ability to easily determine the source of historical data describing the event and the perceived reliability of the resource. This distinction is especially important when there are conflicting accounts of the same event from different sources. These classifications are also important to recognize when attempting to analyze the intricacies as well as study the correlations between attributes of each historical event and to provide the ability for greater inferential potential when attempting to interpret the data. 


\section{UTILIZATION OF HISTORICAL DATA}

Statistical methodology provides the analytical tools necessary to make inferences from the historical data (Muckelroy 1975). With the data classified based on perceived reliability, the data can be selected to be utilized in analysis based on the highest order. While the secondary sources provide the ability to "fill in the gaps" of the historical record where primary sources are lacking, they may not represent the best data to use for inferential analysis.

Campbell (1975) identified that statistical analysis based on Sable Island shipwrecks can provide another level of interpretation not previously available. However, the accuracy of the conclusions based on this analysis is directly related to the reliability of each source utilized.

One example can be gleaned from the attempt to determine how many shipwreck events actually occurred at Sable Island. Prominent estimates suggest the number of shipwreck events at Sable Island range between 185 (Zinck 1979) to over 500 (Cameron 1998), with a common statement suggesting "over 350 recorded shipwrecks since 1583" (Parks Canada 2015, Maritime Museum of the Atlantic 2015). Unfortunately though, these sources do not provide references or document how these numbers were determined.

When the historical sources are combined together they suggest upwards of 445 individual shipwreck events since the $16^{\text {th }}$ century, but when the data is classified based on the type of source and critically interpreted it is realized that a significant number of discrepancies are inherent in the historical data, especially within the secondary resource materials (Mior 2008). When compared to the primary sources, just over two hundred shipwreck events are documented to have occurred at Sable Island since the $16^{\text {th }}$ century, reflecting a more accurate representation of shipwreck events at the island that can be directly referenced and documented. The variability in the number of shipwrecks suggested to have occurred on Sable Island in published sources is one of the many examples where the credulous or naïve use of resource material documenting historical events on Sable Island can invariability lead to misinterpretations and unsubstantiated conclusions.

Many statements made in publications including "a shipwreck could occur at any time" and "especially during winter storms because that is when wrecks were most likely to happen" (Stilwell 2001) can be tested statistically by determining the number of shipwreck events at Sable 
Island per month and the specific weather conditions when each event occurred. Other statements such as those suggesting vessels wrecked on the south side of the island broke up quicker due to the stronger surf (Rosebrugh 1932), or whether these vessels succumbed to the environmental processes quickly (Campbell 1974) or went through a "slow and laborious" process (Patterson 1894) could be investigated in connection to the spatial location of each individual event. While primary sources in general may provide useful data to analyze the weather at the time of a specific shipwreck event, or the month which it transpired, "Authoritative" sources provide a more accurate and reliable data set for investigating the processes influencing the vessels transition into the archaeological record as it would be based on data attributed to someone on the island when the event(s) occurred and written within one year of the event or process described.

The wealth of comparative reference material is also valuable when investigating the historical occupation and settlement on Sable Island, although as alluded to by Campbell (1975), many of these details are unproven. In order to determine a more reliable and accurate representation of the historical occupation on Sable Island the researcher should focus on primary source documentation in an effort to separate the "highly-coloured" tales from reality.

The distinction between these historical sources is also important when designing models for predicting the location of shipwrecks or other archaeological resources reflecting the spatial and temporal human occupation on the island. For example, while a shipwreck map may provide information regarding the initial location of a specific shipwreck event on the island, it is important to investigate the formation of these resources in the archaeological record and the impact of human interaction through activities such as salvage that are documented in the primary source materials.

There are also examples of shipwrecked vessels which have also been significantly impacted by environmental processes on the island. In some instances, evidence from primary source documents, specifically those classified here as "Authoritative", detail examples where the vessel, or components of it, were actually physically re-located by the strength and influence of currents, tides, shifting sands and other environmental processes which influence the unique Sable Island landscape. Therefore, in some cases the archaeological resource should not be expected to be found today in the same location where the 
initial shipwreck event occurred, which is often where it is depicted on historical maps.

If historical sources are to be used for qualitative analysis or predictive modelling in determining the location of archaeologically significant resources on Sable Island, an attempt must be made to validate the accuracy of the historical data. Failure to recognize inherent differences in reliability and classify the historical sources based on perceived accuracy could result in developing false paradigms of historical patterns and providing incorrect positions when investigating the location of specific archaeological resources on the island.

\section{CONCLUSION}

Inferences attempting to define historical phenomena are only as good as the data used in their determination. The approach presented in this paper argues for the classification of the historical sources based on their perceived reliability in an effort to study and analyze the historical events related to Sable Island's maritime history which specifically occurred on the island.

Assembling as many pieces of evidence as possible from a wide range of sources provides the ability to reveal the inaccuracies and distortions of particular sources (Tosh 2015). Each historical source must be evaluated critically based on its merits. The classification of the Sable Island historical sources into six categories based on their perceived reliability provides confidence that the inferences and conclusions can be corroborated. By determining what class of data is best applicable to make specific inferences regarding events which occurred directly on the island, it also provides the ability to strengthen conclusions. Unfortunately for Sable Island research, the primary historical sources available do not document and temporally span the entire period of occupation on the island and therefore gaps in the historical documentary record are unpreventable. Secondary sources can be used to "fill in the gaps", where no comparative primary source material is available. However, such sources should be used with caution and their utilization should be expressly cited if used for analytical interpretations.

Rather than relying on secondary sources, a better alternative would be provided by the accumulation of archaeological data. The archaeological record would not only provide a comparative data set 
for all historical source material, but it could also be used to "fill in the gaps" where reliable historical sources are lacking. Unfortunately, only one archaeological investigation, comprising a four day preliminary surface survey, is known to have been conducted on Sable Island (Finamore 2011). The intention of Parks Canada to conduct future archaeological investigations on Sable Island (Charles Burke pers. Comm.) will not only provide an independent data set for comparison to the historical sources available, but also present intricate details previously undocumented in historical sources and provide the ability to strengthen interpretations and critically investigate the unique historical maritime cultural landscape of Sable Island.

\section{REFERENCES}

Cameron, S. D. (1998). The Living Beach. Macmillan, Toronto, ON.

Campbell, L. (1974). Sable Island, Fatal and Fertile Crescent. Lancelot Press, Nova Scotia.

Campbell, L. (1975). Shipwrecks and the Colonization of Sable Island. Canada: A Historical Magazine, 2(3):16-29.

Campbell, L. (1976). Sir John Wentworth and the Sable Island Humane Establishment. The Nova Scotia Historical Quarterly 6(3):292-309.

Carnochan, J. (1986). Shipwrecked on Sable Island. Niagara Historical Society, Niagara, ON.

Cotter, J.L. (1978). Symposium on Role of Archaeology in Historical Research, Summary and Analysis. In: Schuyler, R.L. (ed.), Historical Archaeology: A Guide to Substantive and Theoretical Contributions. Baywood Publishing Company Inc., New York, pp. 18-19.

Farquhar, J.A. (1980). Farquhar's Luck. Petheric Press Limited, Halifax. Finamore, D. (2011). Report of Investigations: Sable Island Archaeological Survey. Occasional Paper \#2. Institute for Global Maritime Studies, Gloucester MA.

Gould, R.A. (1983). Looking Below the Surface. In: Gould, R.A. (ed.), Shipwreck Anthropology. University of New Mexico Press, Albuquerque, pp. 3-22.

Hume, I.N. (1978). The Why, What, and Who of Historical Archaeology. In: Schuyler, R.L. (ed.), Historical Archaeology: A Guide to Substantive and Theoretical Contributions. Baywood Publishing Company Inc., New York, pp. 203-207.

Maritime Museum of the Atlantic. (2015). Sable Island https://maritimemuseum.novascotia.ca/research/sable-island 30 June 2015.

Mior, A. (2008). The Difficulties, Utilization, Limitations and Potential of a Database Format Based on Primary and Secondary Historical Sources: A Case Study of Shipwrecks and Stranding Events at Sable Island, Nova Scotia, Canada. Unpublished M.MA. Thesis, Flinders University. 
Muckelroy, K. (1975). A systematic approach to the investigation of scattered wreck sites. The International Journal of Nautical Archaeology and Underwater Exploration, 4(2):173-90.

Parks Canada. (2015). Sable Island National Park Reserve http://www. pc.gc.ca/eng/pn-np/ns/sable/visit/visit08.aspx 30 June 2015.

Patterson, G. (1894). Sable Island, Its History and Phenomena. Transactions of the Royal Society of Canada 2:3-49.

Rosebrugh, D.W. (1932). The Graveyard of the Atlantic. Canadian Geographic Journal 4(2):73-84.

Stilwell, R. (2001). The Ethos of Voice in the Journal of James Rainstorpe Morris from the Sable Island Humane Station, 1801-1802. The Edwin Mellen Press, Ontario.

Tosh,J. (2015). The Pursuit of History. Sixth Edition. Routledge, New York. Zinck, J. (1979). Shifting Sands. T \& T Publishing Co., Nova Scotia. 